\title{
A Digital Ethnography of Medical Students who Use Twitter for Professional Development
}

\author{
Katherine C. Chretien, $M D^{1,2}$, Matthew G. Tuck, MD ${ }^{1,2}$, Michael Simon, BA ${ }^{2}$, Lisa O. Singh, PhD ${ }^{3}$, \\ and Terry Kind, MD, MPH ${ }^{24}$
}

'Washington DC Veterans Affairs Medical Center, Washington, DC, USA; ${ }^{2}$ School of Medicine and Health Sciences, George Washington University, Washington, DC, USA; ${ }^{3}$ Georgetown University, Washington, DC, USA; ${ }^{4}$ Children's National Health System, Washington, DC, USA.

BACKGROUND: While researchers have studied negative professional consequences of medical trainee social media use, little is known about how medical students informally use social media for education and career development. This knowledge may help future and current physicians succeed in the digital age.

OBJECTIVE: We aimed to explore how and why medical students use Twitter for professional development.

DESIGN: This was a digital ethnography.

PARTICIPANTS: Medical student "superusers" of Twitter participated in the study

APPROACH: The postings ("tweets") of 31 medical student superusers were observed for 8 months (May-December 2013), and structured field notes recorded. Through purposive sampling, individual key informant interviews were conducted to explore Twitter use and values until thematic saturation was reached (ten students). Three faculty key informant interviews were also conducted. Ego network and subnetwork analysis of student key informants was performed. Qualitative analysis included inductive coding of field notes and interviews, triangulation of data, and analytic memos in an iterative process.

KEY RESULTS: Twitter served as a professional tool that supplemented the traditional medical school experience. Superusers approached their use of Twitter with purpose and were mindful of online professionalism as well as of being good Twitter citizens. Their tweets reflected a mix of personal and professional content. Student key informants had a high number of followers. The subnetwork of key informants was well-connected, showing evidence of a social network versus information network. Twitter provided value in two major domains: access and voice. Students gained access to information, to experts, to a variety of perspectives including patient and public perspectives, and to communities of support. They also gained a platform for advocacy, control of their digital footprint, and a sense of equalization within the medical hierarchy.

CONCLUSIONS: Twitter can serve as a professional tool that supplements traditional education. Students' practices and guiding principles can serve as best practices for other students as well as faculty.

KEY WORDS: social media; undergraduate medical education; internet; twitter; professional development.

Electronic supplementary material The online version of this article (doi:10.1007/s11606-015-3345-z) contains supplementary material, which is available to authorized users.

Published online May 8, 2015
J Gen Intern Med 30(11):1673-80

DOI: $10.1007 / \mathrm{s} 11606-015-3345-\mathrm{z}$

(c) Society of General Internal Medicine 2015

\section{BACKGROUND}

Social media has transformed the way we communicate as a society. Medical students, who have grown up using these technologies, are adept at using social media for personal purposes. Ample attention has been paid to health professionals' unprofessional use of social media, including privacy violations, conflicts of interest, and inappropriate relationships with patients; ${ }^{1-4}$ egregious lapses of professionalism have even resulted in medical school dismissal and state medical board sanctions. ${ }^{2,3}$ However, social media has power that could be harnessed for positive professional purpose. Sharing credible health content, advocacy, career networking, and staying up to date with one's field can all be achieved through use of social media. ${ }^{5,6}$

Twitter is a social media platform with characteristics that can make it useful for professional networking. Its mission is, "To give everyone the power to create and share ideas and information instantly, without barriers."7 Twitter has 271 million active users monthly, and 500 million tweets are sent each day. $^{7}$ Among US online adults ages 18-29 years, $37 \%$ use Twitter, and the majority of users have public accounts. ${ }^{8}$ Users write 140 character-limited messages called "tweets" that can contain links to webpages or other content. Users can interact with other users by following their accounts, and replying to, or mentioning other users in their tweets, thereby creating a network of connections. Many medical organizations and medical journals have Twitter accounts and share relevant information and news. ${ }^{9}$ Physicians on Twitter often post medical or health-related tweets and share information. ${ }^{10}$ Twitter has been identified as a potential learning tool in medical education. ${ }^{11,12}$ Medical education faculty can regularly participate in "chats" on Twitter, and others host Twitter journal clubs to discuss medical articles of interest. Hashtags help categorize tweets for indexing. There are currently active hashtags for medical education (\#meded, \#GME, \#CME) and medical students (\#medstudent).

Medical educators are challenged with guiding medical students along their professional development and giving 
them the tools to succeed in their future careers. Little research has addressed how to leverage social media use for educational and career development. ${ }^{1}$ The goal of this research was to describe how and why medical students are using Twitter for their professional development.

\section{METHODS}

We conducted a digital ethnography with the research question, "What is the culture of medical students who use Twitter for education?" Sub-questions were, "How do they use Twitter?", "With whom do they interact?", and "What do they value?"

An ethnography is a qualitative research framework that seeks to provide a description and interpretation of a cultural group or system. ${ }^{13,14}$ This typically involves prolonged observation of the group, interviews with key informants who can provide insights into the group, and examination of cultural artifacts and documents. Digital ethnography (also called Internet, virtual, or online ethnography) is a research method used to examine the culture of online groups, modifying traditional ethnographic approaches and theory and applying them to the online space. ${ }^{15,16}$

Our target group was medical student "superusers" who used Twitter for educational or professional purposes. We sought to describe this cultural group - their online behavior, their digital networks, and their values.

\section{Identification of Target Group}

We identified potential subjects by: 1) searching key words "medical student" and "med student" on Twitter.com; 2) searching existing public lists of medical students on Twitter collated by individual users; 3) searching relevant hashtags (\#medstudent, \#meded); 4) soliciting referrals by current subjects (chain sampling); and 5) hosting a medical education "tweetchat." A "tweetchat" is a public real-time discussion on Twitter run by a moderator. For this study, two authors (KC and TK) hosted a $1 \mathrm{~h}$ tweetchat in April 2013 on how medical students use Twitter for educational or professional purposes, using the established \#meded tweetchat. This helped to identify students in our target group, and also helped structure our interview guides.

All identified students were added to a general medical student Twitter list shared among the investigators. The number of students on this list was fluid, as students were continually added or removed (if not actually a student, for example), with a total of 293 at study closure. From the general medical student list, students were added to a superuser list if they were observed to post professional content (for instance, sharing a journal article or live-tweeting a medical conference), interact with other medical students and faculty, and/or participate in professional Twitter "chats." The research team met weekly to establish consensus on who should be added to the superuser list. To be included, users had to be current medical students in the US. Current students at our medical schools were excluded. The final superuser list as of May 2013 included 31 subjects.

\section{Structured Observations}

Four investigators, including two expert Twitter users (KC and TK) and two novice users (MS and MT), observed tweets of the 31 superusers and of the general list of medical students for 8 months (May-December 2013), taking structured field notes, guided by key dimensions of descriptive observations (Space, Actors, Activities, Objects, Acts, Events, Time, Goals, Feelings). ${ }^{17,18}$

\section{Semi-Structured Interviews with Key Informants}

Using purposive sampling, key informant superusers were identified for interviews. We used a semi-structured interview guide designed to explore their use of Twitter, the nature of their interactions with other users, and what they valued from their use (Appendix). Subjects were invited for interview via email and provided an institutional reviwe board (IRB)-approved information sheet on study procedures. Their agreement to participate served as consent. Interviews were digitally audio-recorded, and with the exception of personal identifiers, transcribed by an external service. At the conclusion of each interview, major themes were reviewed with the participant for member-checking. Interviews continued until saturation of themes was reached $(n=10)$. For data triangulation, three faculty key informants, identified through student key informant interviews, were also interviewed. Faculty informants were asked to describe their interactions with students on Twitter, how they felt students used Twitter for educational purposes, and student best practices. All subjects interviewed were offered $\$ 25$ for their participation. Interviews lasted between 30 and $60 \mathrm{~min}$.

\section{Network Analysis}

In order to understand students' use of Twitter, we extracted total number of tweets, number of followers, number followed, and for a subset of tweets, analyzed content for URLs, retweets, and hashtags for each key informant. Further, to understand and describe the virtual community in which students "live" and "interact," we conducted two forms of network analysis: 1) an ego network (local network of an individual) analysis of key informants, and 2) a subnetwork analysis of key informants who were connected to each other. For the ego network analysis, we computed the centrality (ego behavior metrics) degree and clustering coefficient. The degree is the number of connections the individual (node) has, or the size of the local neighborhood. Clustering coefficient (value range 0 1) is a measure of the connectivity a local neighborhood. Higher clustering coefficients indicate a well-connected neighborhood and potential for rapid information dissemination.

Subnetwork analysis focuses on the characteristics of the network itself. The metrics we computed were subnetwork density, number of triangles, and subnetwork diameter. These 
metrics help describe the connections between the key informants and the ability to transmit information within this group. We used R, Node XL (an Excel-based tool) and Gephi (network analysis and visualization software) for the network analysis.

\section{Qualitative Analysis and Trustworthiness}

The team met monthly to discuss observations and review interview transcripts. Memos captured emerging themes and analytic insights from comparing and contrasting the various forms of data (triangulation). We compiled a list of codes that emerged inductively from the data and applied these to all field notes and interview transcripts. Each transcript was coded independently by two investigators; in addition, to add consistency, a single investigator (KC) coded all transcripts. Codes were compared and any discrepancies were resolved through discussion; subsequent modification of codes resulted. Representative and exemplary quotes were highlighted for each code. Following principles of inductive analysis ${ }^{19}$ and incorporating network analysis results, we constructed a description of the target group.

We bolstered trustworthiness in several ways: 1) triangulation of data sources and methods; 2) inclusion of expert and novice Twitter users and a medical student on the researcher team; 3) member checking of main themes at the end of the interviews; 4) creation of an audit trail to document team decisions and discussion; 5) peer-review of transcripts with feedback given to interviewers; and 6) use of multiple interviewers. Qualitative data was managed with NVivo10 (Cambridge, MA). The Washington DC Veterans Affairs Medical Center Institutional Review Board approved the study.

\section{RESULTS}

Of the 31 superusers, 17 were female, 13 male, and for one, gender was not specified. Thirteen (41\%) linked to their blogs. The majority $(25,81 \%)$ appeared to include their real name on their Twitter prolife. They represented all regions of the US and all years of medical school. For the ten student key informants, seven were female and three were male. They were in their first year (2), third year (2) and fourth year (6) of medical school. They lived in large cities on the East Coast, West Coast, Midwest, and Southern regions of the US.

Results are organized around how students use Twitter (practices), their interactions (network analysis), and why they use it (value).

\section{Twitter Practices of Superusers}

Overall, students were active Twitter users who were often early adopters of Twitter use among their medical school classmates. Many also had a personal blog. They followed other medical students, medical faculty, medical journals, medical and news organizations, and other health professionals, among others.
Medical student superusers used Twitter thoughtfully and were guided by the purpose of their use. They were mindful of their professionalism online and were careful not to mention specific patients to protect patient privacy. Many mentioned thinking twice before tweeting to avoid potential misinterpretation of what they meant to say. In general, they avoided venting and possible inflammatory statements and were aware of their public image. Their tweets included both professional and personal content.

"I'm a real-life person. I'm not a made-up person. I don't think that that detracts from my professional interaction - that's just me." (Key informant 8)

"I try to go about my social media as if I was actually interacting with a patient. So if I were to see a patient in the office ...you do share a little bit about your personality so that's where I post things about myself and my personal life." (Key informant 9)

Superusers also practiced "good Twitter citizenship" by contributing to conversations, sharing helpful information with others, and being cognizant of posting etiquette.

Students identified faculty role models on Twitter who helped guide their own use in terms of how to share information and how to respond to challenging situations with other users. We did not observe any unprofessional content posted. See Box 1 for a summary of superusers' Twitter practices.

\section{Box 1. Twitter Practices of Medical Student Superusers}

Know purpose for use

Mindful of online professionalism Avoid mentioning specific patients

Think twice, tweet once

Avoid venting

Avoid inflammatory statements

Aware of public image

Not strictly medical content, show "personality"

Practice "good Twitter citizenship"

Contribute to conversations

Share information

Aware of posting etiquette

Identify faculty role models for use

\section{Network Analysis of Key Informants}

As of July 2014, the student key informants followed a median of 489 (range 56-6425) Twitter users. They, in turn, were followed by a median of 1770 (range 403-11169) users. The key informants posted a median 7371 tweets (range 417221057) since their Twitter debuts (which predated our study in all cases). Analysis of a subset of 2074 tweets (Twitter imposes restrictions on how much data can be imported) revealed that 553 contained URLs, 423 were re-tweets, and 647 contained one or more hashtags (Table 1). 
Table 1 Hashtags Used by Medical Student Key Informants in a Subset of 2074 Tweets

\begin{tabular}{|c|c|c|}
\hline Hashtag & $\begin{array}{l}\text { Frequency } \\
\text { count }\end{array}$ & Comment \\
\hline \#socaphealth & 69 & $\begin{array}{l}\text { Socap Health conference; goal } \\
\text { is to examine the roles of } \\
\text { entrepreneurs, investors, and } \\
\text { funding bodies in the larger } \\
\text { public health ecosystem. }\end{array}$ \\
\hline \#meded & 63 & $\begin{array}{l}\text { Medical education; weekly } \\
\text { Twitter chat. }\end{array}$ \\
\hline \#hcsm & 31 & $\begin{array}{l}\text { Healthcare communications } \\
\text { and social media; weekly } \\
\text { Twitter chat. }\end{array}$ \\
\hline \#fmrevolution & 26 & $\begin{array}{l}\text { Family medicine revolution; } \\
\text { Re-branding campaign started } \\
\text { by family med residents to } \\
\text { promote family medicine } \\
\text { careers. }\end{array}$ \\
\hline \#ase2013 & 25 & $\begin{array}{l}\text { Association for Science } \\
\text { Education } 2013 \text { conference }\end{array}$ \\
\hline \#sdoh & 23 & Social determinants of health \\
\hline \#fitstats & 20 & $\begin{array}{l}\text { Fitness statistics derived from } \\
\text { popular fitness app }\end{array}$ \\
\hline \#disruptinginequality & 16 & $\begin{array}{l}\text { Disrupting inequality; } \\
\text { advocacy for social change }\end{array}$ \\
\hline \#medschool & 16 & Medical school \\
\hline \#medstudent & 15 & Medical student \\
\hline \#residency & 11 & Residency \\
\hline \#usavsbel & 11 & $\begin{array}{l}\text { USA versus Belgium World } \\
\text { Cup game }\end{array}$ \\
\hline \#commdev & 10 & Community development \\
\hline \#obgyn & 10 & Obstetrics/Gynecology \\
\hline
\end{tabular}

*Tweets occurred between January 2013 and July 2014. No hashtags were excluded

Figure 1 shows the full followers network on the key informants. The ten key informants connect to 40,091 other individuals on Twitter. Based on the average directed degree (2) and the low clustering coefficients ( 0.054 directed, 0.102 undirected), key informant networks have limited overlap.
They are not the center of a broader community structure, although they may participate with multiple separate overlapping communities. This suggests an opportunity for extensive information dissemination (access to different groups to share information with).

Figure 2 visually highlights the connectivity between key informants from the ego and subnetwork analysis. Overall, the informant network is well connected (clustering coefficient of 0.851 , average directed degree 9). None of the males are connected to each other, but the majority of females follow each other. The overall subnetwork density is 0.46 , high for a Twitter subnetwork. Subnetwork analyses support that students maintain large, diverse networks that have other key informants in them, but otherwise interact with different subgroups of people.

\section{Value for Medical Students}

Twitter served as a professional tool, something that supplemented their medical school education.

"I just think it's helped me grow as a professional because...there is more to who you become as a physician that can enable better patient care that doesn't happen just with textbooks." (Key informant 4)

Students derived value from Twitter in two main domains of Access and Voice (Fig. 3).

Access. Medical student superusers gained access to information, to experts, to a variety of perspectives including patient/public perspectives, and to communities.

Twitter is a way that these students accessed information. They used it to stay up to date with general news and their fields of interest.

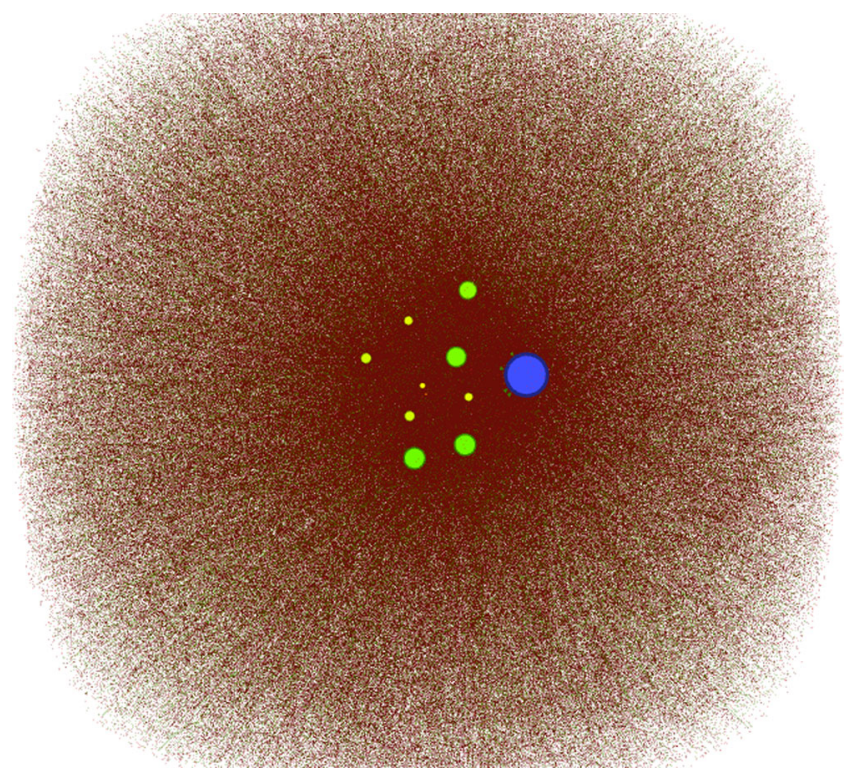

Figure 1 Full followers network of the key informants. The size and color of the node correspond to the degree (number of connections) of the node. (Average degree $=2$; clustering coefficient, directed $=0.054$; clustering coefficient, not directed $=0.102$; number of nodes $=40,101$; number of edges $=61,602$ ). 


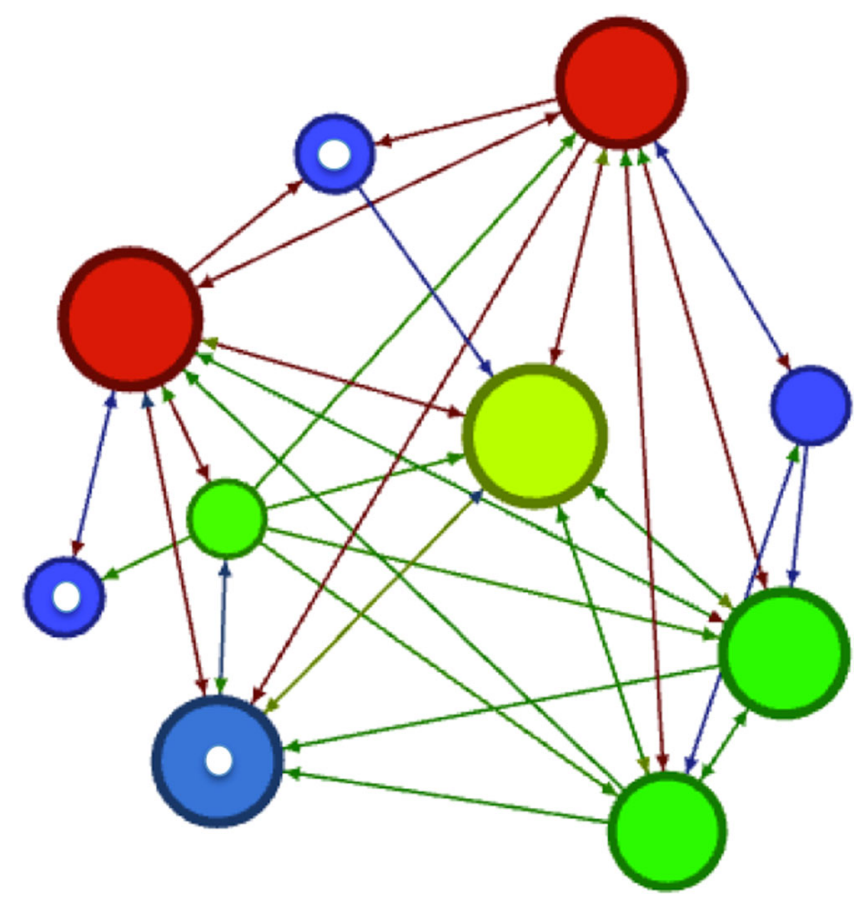

Figure 2 Key Informant Network. The size of the node corresponds to the number of key informant followers the node has. A large node indicates that many key informants follow that node. The color of each node maps to the clustering coefficient. A red node indicates a low clustering coefficient a green node indicates a mid-range clustering coefficient, and a blue node indicates a high clustering coefficient. It is not surprising that nodes with a higher degree have a lower clustering coefficient. Finally, a white dot in the middle of a node indicates that the key informant represented by that node is male. (Average degree $=9$; clustering coefficient $=0.851$; number of triangles, no direction $=42$; number of triangles, with direction $=69$; network diameter $=3$ ).

"It helps keep me up to date on what's going on in the world, in the world of medicine in this country, with healthcare reform, and everything." (Key informant 3) "I definitely know about various articles that tend to be of importance in my field before other people." (Key informant 7)

Students on Twitter find value in the ability to access content experts in medicine with whom they otherwise would not be able to connect. One key informant asked a question on Twitter during a lecture and had an international expert respond with the answer within 2 min-before the class instructor could look up the answer. Other key informants described having access to medical content experts during Twitter chats or following experts who tweeted clinical pearls.

Twitter provided some students with opportunities for professional collaborations, allowing them to connect with other medical students with similar interests.

Access to individuals with different perspectives was of particular value for students, including others' opinions about health policy, medical education, and the medical profession in general. For many key informants, being able to gain the patient perspective was invaluable to their professional development.

“...looking at their feeds and hearing them talk about their experiences has really changed the way that I see the personal side of patients- how the medical system has worked for them, and that's really not something that we get [in training]." (Key informant 1)

"[I] ask them a lot of questions about how they've been treated by their doctors...It's kind of like an opportunity to just interview a lot of patients without having to wait until third year." (Key informant 6)

Beyond the patient perspective, Twitter also allowed them a broader context by which to understand medicine, outside of the patient-physician dynamic.

Through Twitter, students gained access to communities of learning and support. One key informant shared, "The most valuable thing for me is a sense of community, because as an older medical student there's just not a lot of community."

Students described having a community of medical students that congratulate each other when milestones are reached, help each other study for exams and experience medical school together.

"We all kind of support each other and... are there to cheer each other on as we go through medical school." (Key informant 10)

"We share information all the time. We share articles, we share study techniques." (Key informant 8)

Students interacted with faculty on Twitter who provided advice, encouragement and virtual mentorships.

"We had basically a public discussion where I just asked her questions about what is the right way to talk 


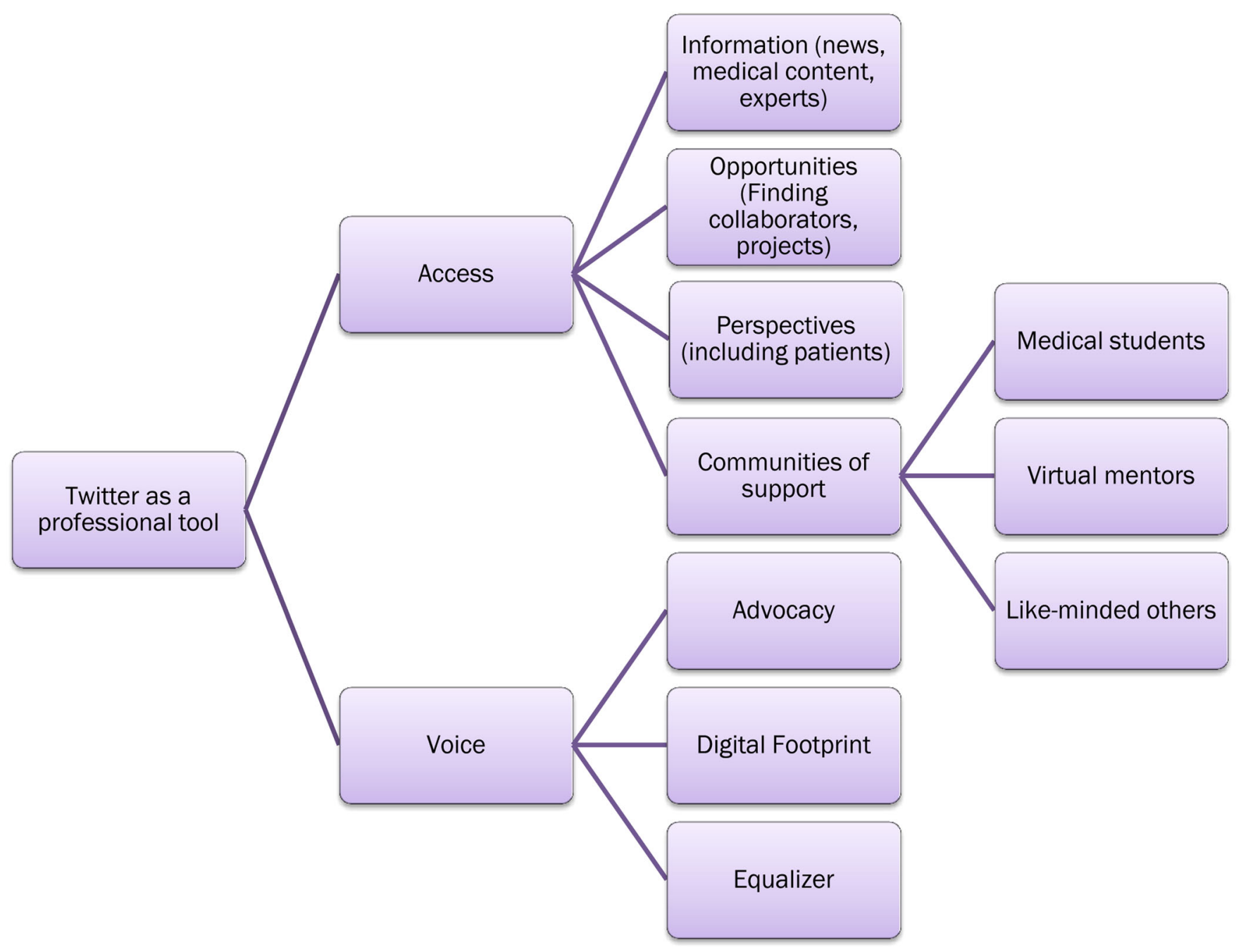

Figure 3 Value for medical students.

to patients about this, and what is the right word choice that won't be offensive?" (Key informant 6)

"...phenomenal advice from people who are very accomplished...I got to shadow one of them." (Key informant 5)

"...being able to follow older physicians [is] the most valuable, just getting a glimpse into what my life could be like when I'm a doctor." (Key informant 3)

Students also connected with communities of likeminded others, such as communities centered on personal interests and hobbies or those who carried similar views. For some, these communities served as sources of inspiration.

For instance, one student commented on the impact of a Twitter community on her decision to pursue a primary care specialty.

"...coming from my institution... the attendings weren't always the most supportive in trying to persuade people to go into primary care so having that online group of people that was really supportive and giving advice to each other and patting each other on the back - I think that was super inspiring." (Key informant 9)

These communities of like-minded others have helped students maintain their ideals.

"I want to make a difference ... Twitter gave me a community where I could like not like feel alone in doing that. How Twitter has influenced me is that it really connected me to other people that believe that we can make things better. "(Key informant 8 )

Voice. Twitter also provided students value by giving them a voice in the domains of advocacy and an enduring digital footprint, and was an equalizer of power.

Some students used Twitter as a platform to support political issues and to share their health policy opinions. It helped 
them develop their own voice and engage with others outside of their comfort zones.

"I think it's important for everyone to have a voice and honestly I think a lot of times medical students really need to have the loudest voice of all, because they're the people in the transition zone between being a patient and a receiver of healthcare to being a healthcare provider." (Key informant 8)

Twitter allowed medical students a way to craft their digital footprint in a positive way.

"I want them to search for me and find a consistent presence that is positive." (Key informant 7)

Finally, Twitter served as an equalizer and a "leveling force in terms of power hierarchy" (Key informant 5).

"A lot of times I don't even know if ... the person that I've talked to is faculty or student or resident... it's often just a conversation... the great equalizer." (Key informant 7)

"It kind of disrupts who gets a voice, like who gets to talk about what." (Key informant 4)

\section{DISCUSSION}

For this group of students, Twitter served as a professional tool, giving them access and voice. It provided added value from the traditional medical school curricula; they gained support, networking opportunities, mentorship, and learning. These students do not represent the majority of medical students on Twitter, but a subculture who were often pioneers in their use of Twitter for professional purpose.

We were particularly moved by students' interactions with patients. Note that these were not patients the students had cared for clinically, but people on Twitter who self-identified as patients with certain disease conditions. Students seemed to greatly value hearing patient perspectives, gaining greater cultural sensitivity and understanding of what it is like for patients living with their conditions. Social media, with its many virtual patient communities, could be a resource for medical students to better understand the patient experience.

The posting practices of these superusers align with guiding principles of online professionalism derived from national consensus statements and guidelines, ${ }^{20,21}$ research on stakeholders' perspectives of what is appropriate and what is inappropriate to post, ${ }^{22-25}$ and expert opinion. ${ }^{6,26}$ These include safeguarding patient privacy, "pause before posting," avoiding inflammatory material, and carefully considering material that is to be posted for public consumption. The one area where superusers deviated from published guidance is the advice to maintain separate personas or accounts for personal and professional purposes. Superusers included parts of their personal lives on their accounts and felt this added to their authenticity. Of note, others have disagreed with recommendations to separate professional and personal online identities, arguing that this is simply not possible on the Internet, is inconsistent with the concept of professional identity, and could be potentially harmful. ${ }^{27}$

In comparison to the average Twitter user, the key informants in this study had more followers. The majority of Twitter users have fewer than 50 followers whereas the median number of followers for student key informants was $1770 .{ }^{28}$ In Twitter, the amount of community structure is correlated with the number followers a person has. ${ }^{30}$ Network analysis metrics of the key informant subnetwork reflect a social network community as opposed to an information network community. ${ }^{29}$ In other words, the students we studied tend to have social, reciprocal relationships on Twitter more so than simple information retrieval, and this may account for some of its added value.

In a systematic review of social media use in medical education that included 14 studies incorporating social media in formal curricula, Cheston et al. cited opportunities of promoting learner engagement, feedback, collaboration and professional development. ${ }^{30}$ Some medical educators have advocated for the use of Twitter, specifically, as a professional tool. ${ }^{11,12}$ In their pilot studies, George and Dellasega noted that Twitter, as one of several social media platforms incorporated into two humanities courses for fourth-year students, augmented learning and collaboration and allowed real-time communication between learners and instructors outside the classroom. ${ }^{31}$ Little research exists about how medical trainees or physicians actually use social media for informal learning and professional development. The present study thus fills a gap in the literature.

Connectivism is a learning theory that supports the use of Twitter for learning. ${ }^{32}$ Connectivism relates learning as a process of connecting information sources; nurturing these connections is needed for continual learning. A diversity of perspectives and opinions fuel learning and knowledge, and the capacity to increase one's knowledge is more important than what one currently knows. ${ }^{32}$ Managing and filtering the information on Twitter and other social media platforms in order to obtain the most current information in students' fields of interest may be a key competency for today's learners that is not regularly addressed in undergraduate medical curricula. ${ }^{33}$ Future research could explore how students critically appraise information on Twitter or other social media sites, as well as the quality of students' learning.

The ability and desire to use Twitter as a professional tool may be specific to certain students. In one study of osteopathic medical students, students with learning styles self-assessed as active, global, intuitive and/or visual were more likely to access online educational materials than those whose learning styles were reflective, sensing, sequential, and/or verbal. ${ }^{34}$ In addition, individual student preferences and characteristics 
may dictate whether students choose to use Twitter for professional development. Many in our sample also had a blog; this could indicate particular comfort in sharing ideas publicly?

This study has potential limitations. Digital ethnography is a newer research method; diverse approaches have been used to study the Internet with an ethnographic perspective. ${ }^{16}$ Key informants may not have disclosed fully in interviews if concerned about anonymity, though efforts were made to reduce this possibility. Expert Twitter user faculty investigators may have carried pre-existing assumptions about student use; to test these assumptions, the team also included novice users and a medical student. Also, we limited network analysis to key informants (instead of the larger group of superusers) given we had only the informants' expressed consent to be included in our study.

In conclusion, medical students who regularly used Twitter as a professional tool were doing so with thoughtfulness and purpose. Twitter allowed them access and voice that supplemented their medical school experience. Their Twitter practices can serve as best practices for other students as well as faculty, in their career lifelong learning and professional development.

Acknowledgements: This work was funded by the CDIM-inTime Small Grants Program and presented in poster form at Academic Internal Medicine Week on 12 September 2014 in Washington, DC.

Conflicts of Interest: The authors declare that they do not have a conflict of interest.

Corresponding Author: Katherine C. Chretien, MD; Washington DC Veterans Affairs Medical Center, 50 Irving Street, NW, Washington, DC 20422, USA (e-mail: Katherine.Chretien@va.gov).

\section{REFERENCES}

1. Fenwick T. Social media and medical professionalism: rethinking the debate and the way forward. Acad Med J Assoc Am Med Coll. 2014;89(10): 1331-1334.

2. Greysen SR, Chretien KC, Kind T, Young A, Gross CP. Physician violations of online professionalism and disciplinary actions: a national survey of state medical boards. JAMA. 2012;307(11):11411142 .

3. Chretien KC, Greysen SR, Chretien J-P, Kind T. Online posting of unprofessional content by medical students. JAMA. 2009;302(12):13091315 .

4. Chretien KC, Tuck MG. Online professionalism: A synthetic review. Int Rev Psychiatry Abingdon Engl. 2015: 1-12.

5. Greysen SR, Kind T, Chretien KC. Online professionalism and the mirror of social media. J Gen Intern Med. 2010;25(11):1227-1229.

6. Chretien KC, Kind T. Social media and clinical care: ethical, professional, and social implications. Circulation. 2013;127(13): 1413-1421.

7. Twitter, Inc. About Twitter. 2015. https://about.twitter.com/company. Accessed March 23, 2015.

8. Duggan M, Ellison NB, Lampe C, Lenhart A, Madden M. Demographics of Key Social Networking Platforms. Pew Res Cent Internet Sci Tech. 2015. http://www.pewinternet.org/2015/01/09/demographics-of-key-socialnetworking-platforms-2/. Accessed March 24, 2015.

9. Mishori R, Singh LO, Levy B, Newport C. Mapping physician twitter networks: describing how they work as a first step in understanding connectivity, information flow, and message diffusion. J Med Internet Res. 2014;16(4), e107.

10. Chretien KC, Azar J, Kind T. Physicians on twitter. JAMA. 2011;305(6):566-568.

11. Forgie SE, Duff JP, Ross S. Twelve tips for using twitter as a learning tool in medical education. Med Teach. 2013;35(1):8-14.

12. Kind T, Patel PD, Lie D, Chretien KC. Twelve tips for using social media as a medical educator. Med Teach. 2014;36(4):284-290.

13. Cresswell J. Qualitative inquiry and research design: choosing among five traditions. Thousand Oaks: Sage Publishing; 1998.

14. Reeves S, Peller J, Goldman J, Kitto S. Ethnography in qualitative educational research: AMEE Guide No. 80. Med Teach. 2013;35(8):e1365e1379.

15. Murthy D. Digital ethnography: an examination of the use of new technologies for social research. Sociology. 2008;42:837.

16. Dominguez D, Beaulieu A, Estalella A, Gomez E, Schnettler B, Read R. Virtual Ethnography. Forum Qual Soc Res. 2007;8(3).

17. Spradley J. Participant observation. New York: Holt, Rinehart \& Winston; 1980.

18. Robson C. Real world research. Malden: Blackwell; 2002.

19. Miles M, Huberman A. Qualitative data analysis. 2nd ed. Thousand Oaks: Sage; 1994.

20. Farnan JM, Snyder Sulmasy L, Worster BK, et al. Online medical professionalism: patient and public relationships: policy statement from the american college of physicians and the federation of state medical boards. Ann Intern Med. 2013;158(8):620-627.

21. American Medical Association. Opinion 9.124 - Professionalism in the Use of Social Media. AMA Code Med Ethics. 2011. http://www.ama-assn.org/ ama/pub/physician-resources/medical-ethics/code-medical-ethics/opinion9124.page. Accessed March 24, 2015.

22. Chretien KC, Farnan JM, Greysen SR, Kind T. To friend or not to friend? social networking and faculty perceptions of online professionalism. Acad Med J Assoc Am Med Coll. 2011;86(12):1545-1550.

23. Kind T, Greysen SR, Chretien KC. Pediatric clerkship directors' social networking use and perceptions of online professionalism. Acad Pediatr. 2012;12(2): 142-148

24. Jain A, Petty EM, Jaber RM, et al. What is appropriate to post on social media? Ratings from students, faculty members and the public. Med Educ. 2014;48(2):157-169.

25. Greysen SR, Johnson D, Kind T, et al. Online professionalism investigations by state medical boards: first, do no harm. Ann Intern Med. 2013;158(2): 124-130.

26. Mostaghimi A, Crotty BH. Professionalism in the digital age. Ann Intern Med. 2011:154(8):560-562.

27. DeCamp M, Koenig TW, Chisolm MS. Social media and physicians' online identity crisis. JAMA. 2013;310(6):581-582.

28. Beevolve Inc. An Exhaustive Study of Twitter Users Across the World. 2012. http://www.beevolve.com/twitter-statistics/. Accessed March 24, 2015.

29. Myers S, Sharma A, Gupta P, Lin J. Information network or social network? The structure of the Twitter follow graph. 2014;493-498.

30. Cheston CC, Flickinger TE, Chisolm MS. Social media use in medical education: a systematic review. Acad Med J Assoc Am Med Coll. 2013;88(6):893-901.

31. George DR, Dellasega C. Use of social media in graduate-level medical humanities education: two pilot studies from penn state college of medicine. Med Teach. 2011;33(8):e429-e434.

32. Siemens G. Connectivism: a learning theory for the digital age. J Instr Technol Distance Learn. 2005;2(1):3-10.

33. Sandars J. Developing competences for learning in the age of the internet. Educ Prim Care Off Publ Assoc Course Organ Natl Assoc GP Tutors World Organ Fam Dr. 2009;20(5):340-342.

34. Halbert C, Kriebel R, Cuzzolino R, Coughlin P, Fresa-Dillon K. Selfassessed learning style correlates to use of supplemental learning materials in an online course management system. Med Teach. 2011;33(4):331-333. 